This item was submitted to Loughborough's Research Repository by the author.

Items in Figshare are protected by copyright, with all rights reserved, unless otherwise indicated.

\title{
A systems approach for balancing internal company capability and external client demand for integrated product-service solutions
}

PLEASE CITE THE PUBLISHED VERSION

PUBLISHER

(c) IEEE

VERSION

VoR (Version of Record)

\section{LICENCE}

CC BY-NC-ND 4.0

\section{REPOSITORY RECORD}

Morcos, Maged, and Michael Henshaw. 2019. "A Systems Approach for Balancing Internal Company Capability and External Client Demand for Integrated Product-service Solutions”. figshare. https://hdl.handle.net/2134/5393. 
This item was submitted to Loughborough's Institutional Repository (https://dspace.lboro.ac.uk/) by the author and is made available under the following Creative Commons Licence conditions.

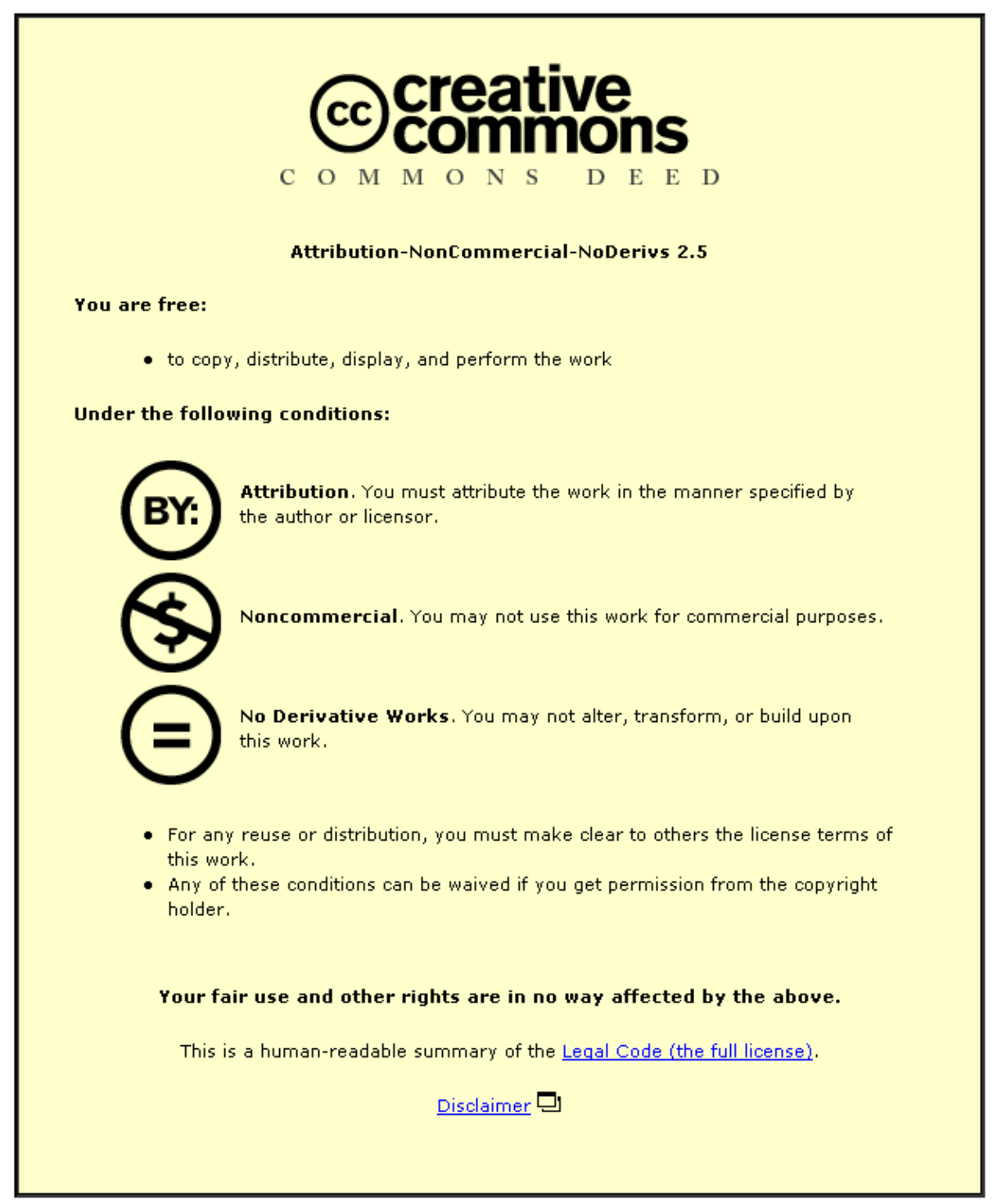

For the full text of this licence, please go to: http://creativecommons.org/licenses/by-nc-nd/2.5/ 


\title{
A Systems Approach for Balancing Internal Company Capability and External Client Demand for Integrated Product-Service Solutions
}

\author{
M. S. Morcos and M. J. D. Henshaw (Member, IEEE)
}

\begin{abstract}
This paper offers a systems thinking approach for easing the tension between the front office (responsible for meeting client requirements) and the back office (responsible for providing necessary company capabilities) in the transformation of a product-focused company to a product-service provider. These parts of the company may have competing objectives and cultures that must be reconciled to ease the train of tension between them. We propose consideration of these parts as individual systems within a system of systems construct and suggest the creation of a central function as a third system, the purpose of which is to manage the interoperability between the front and back offices. The central function provides a leadership role and an integrating function for the company, the outcome of which should be firstly to act as a catalyst for changing the mindset of individuals within the organization towards the product-service endeavour and, secondly, a strategic balance in terms of implementing policy in accordance with the changing external business environment. The management of this balance between the product system and the service system within the same organization is a crucial element of sustainability.
\end{abstract}

\section{INTRODUCTION}

$\mathrm{I}_{\mathrm{c}}^{\mathrm{n}}$ n competitive markets the business paradigm for many companies is shifting from being product-focused to a product-service mix, in which the company develops the physical products and provides the maintenance, or throughlife care of those products to clients. Companies making this change to their competitive offering face a significant challenge that is not present in the same manner with organizations that are either product or service oriented. The managers must cope with two internal compelling forces: the client focused part of the company that is responsive to client needs and must provide immediate satisfaction as a service activity and the product focused part of the company, concerned with internal company capabilities and longer term delivery notions. Although, in principle, these two parts of the company should not be in opposition, it is clear that the business ethos and respective managers' objectives may be in conflict (see for example [1]). This conflict is

Manuscript received March 1, 2009. This work was supported by the UK Engineering and Physical Sciences Research Council and BAE Systems under the S4T programme (Service Support Solutions: Strategies and Transformation)

Dr. M. S. Morcos is with the Electronic and Electrical Engineering Department, SEIC University of Loughborough, Leicestershire, LE11 3TU, UK, (e-mail: m.morcos@lboro.ac.uk).

Prof. M. J. D. Henshaw. is with the Electronic and Electrical Engineering Department, SEIC University of Loughborough, Leicestershire, LE11 3TU, UK, (e-mail: m.j.d.henshaw@lboro.ac.uk). exacerbated in the case of an organization transforming from product to product-service mix.

In this paper, we explore the reasons for the conflict and assert that a systems perspective is required to resolve the conflict. We propose a central function that has attributes of systems thinking, leadership, and integration as a means of harmonizing these opposing forces within the organization, and provide a model that can be used to manage the transformation in such a way that client satisfaction can be maintained during transformation and beyond. We assert no particular form for the central function, but we note that it should be the catalyst for a change in corporate mindset as the company changes its business paradigm.

To satisfy both forces, managers must manage, control, and exploit three business drivers: 1) create a sustainable profitable position for the company through offering integrated product-service solutions that create co-value propositions to the client as well as to the company, 2) maintain this position by balancing external client demand and internal company capability, and 3) ease the tensions between the two forces to achieve a win-win position for both parties.

We can consider a company that has moved some way towards the product-service mix, from a product focused base, as comprising two parts: the Front Office (FO) that must be properly empowered and the Back Office (BO) that must also develop and exploit company capabilities. A third part, that we term the Central Function (CF), should be created. This may be a virtual part of the organization, or a real entity (a central office in the terminology above), but is made up of two parts. A leadership part that sets priorities, strategies and policies is a part of the strategic effort of the company. An infrastructure part has the necessary activities, roles and networks required for enhancing the company's various capabilities. The considerations for this central function are the main thrust of this paper. In particular, we set forth the need for a systems perspective within this central function and identify some important characteristics of it.

The performance of companies offering service solutions varies dramatically from one organization to another, as can be seen from case studies in the literature [2]-[3]-[4] and [5]. For instance, Citigroup and IBM have previously succeeded in some cases through the provision of solutions that accounted for most of their profits. Global Relationship Bank (GRB) of Citigroup, for instance, succeeded in the past by offering its multinational clients a comprehensive array of international banking products, integrated and customized 
to meet their ever-changing needs everywhere in the world [2], [4]. On the other hand, Xerox, HP and Lucent were less successful in achieving this mix of solutions. Further examples are given in [2]-[3]-[4] and [5]. To deliver successful service solutions a company must integrate its internal system to ensure that the value of the integrated system to the client is greater than the sum of the component parts [3]. This is a systems approach, which managers must adopt to achieve a good balance between Back Office and Front Office and deliver 'added value' for the client and the company itself [2]. This paper offers a systems thinking approach that may be extended to a systems methodology to ease the tension between Back Office and Front Office.

\section{REQUIREMENTS FOR PRODUCT-SERVICE SYSTEMS}

\section{Product-Service Systems (PSS) Concept and Definition}

The Product-Service Systems (PSS) concept can be considered as a market proposition that extends the traditional functionality of a product by incorporating additional services [6]. The emphasis in PSS is on the 'sale of use' rather than the 'sale of product'. Hence the concept of PSS can be viewed as a special case of servitization, where the client pays for using an asset, rather than its purchase, and so benefits from reorganization of risks, responsibilities and costs traditionally associated with ownership. Similarly the supplier/manufacturer can improve its competitiveness as these solutions can be clearly differentiated from product-based offerings, while simultaneously retaining asset ownership that can enhance utilization, reliability, design, and protection [3]. Most authors see the purpose of a PSS as a competitive proposition, and so directly refer to the need for customer satisfaction and economic viability. In addition, many link PSS with achieving sustainability, e.g. [7]-[8]-[9] and [10] but only [10] sees this as the ultimate goal.

In recent years, different literatures have attempted to give a definition of PSS; see [6] for different definitions from different authors. In its broadest terms, PSS are a combination of products and services needed to jointly fulfill customer needs. The exact definition adopted in this work defines PSS as 'a system of products, services, network partners and supporting infrastructure that is economically feasible, competitive and satisfies customer needs' [6].

Reference [7] adds further clarity by also defining the key elements of a PSS as follows: 1) Product: a tangible commodity manufactured to be sold. 2) Service: an intangible activity (work) done for others with an economic value and often done on a commercial basis. 3) System: a collection of elements including their relations. In this sense the integration of product and service means that a supplier integrates products and/or services to deliver an especially useful outcome. Hence, in accordance with the requirement for building an efficient PSS, managers should shift to a more holistic approach and view the two sides of the business - company internal capability and client need - to blend both parts into a systems methodology that integrates all parts and stakeholders such that a balance of company stability is maintained. Supporting evidence of these benefits can be seen in the literature [2]-[3] and [5], and so effective systems engineering of the whole organization is required.

\section{TRADITIONAL VIEW}

Traditionally, in a product focused organization, management minds will be set on controlling and directing the company's internal capabilities, resources, and employees to manufacturing products that can be delivered with functionality, quality, and speed to satisfy certain client needs. This view tends towards organizational structures that can be described as comprising two units (illustrated schematically in Fig. 1): the Front Office that is the part of the company visible to the clients and in direct contact with them, such as marketing, user support, or after-sales service teams. The Back Office could be described as all parts of the company to which the client does not have access. This includes all internal processes such as production, logistics, warehousing, sales accounting, human resource management, etc. The Back Office is more in contact with suppliers, partners, and other sub-contractors.

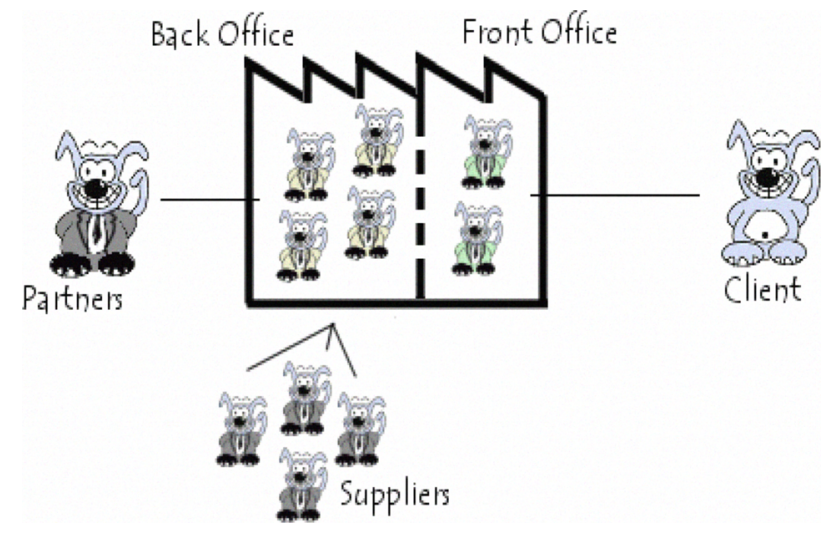

Fig. 1. Front Office and Back Office - Schematic Drawing

\section{The Train of Tension between the Front Office and Back Office}

In reality, the Back Office and Front Office of the traditional view are not entirely separate, because the teams in charge of the client relationship know at least a minimum of information regarding the process of manufacturing the product. In turn, the team in the Back Office dedicated to product design must be kept informed of problems that are encountered by the client or the needs of the client, in order that they can travel a circle of continuous improvement to provide better services. The tension arises because of a number of factors that have the possibility of being accentuated during a transformation from product to PSS. The timescales for the Front Office and Back Office are different. The Front Office focused on service must deliver the required service immediately upon request, but the service must be delivered in such a way for many years. Thus delivery occurs on the short timescale, but maintenance of relations must take place on a continuous basis. The Back Office, by contrast, works towards an in-service date for its product and will generally be concerned with delivery over longer timescales. Furthermore, whereas the Front Office 
will often need to share certain information to allow the service provider and the client to co-create value, the Back Office may have to protect information and intellectual property for long term benefits and the maintenance of commercial discriminators. Thus the Back Office will in general work to longer timescales than the Front Office, but will also have less immediate concern about the maintenance of long-term relationships.

There is also a considerable cultural difference between Front Office and Back Office. The Front Office is clientfocused as noted above, but the Back Office may have greater concerns for internal capability. The design and engineering functions that feature within the Back Office may be staffed by people who are passionate about engineering and the particular product. There are likely to be differences between creating the perfectly engineered product and developing a product that is sufficient.

Fig. 2. Company Current Management Dual Focus and

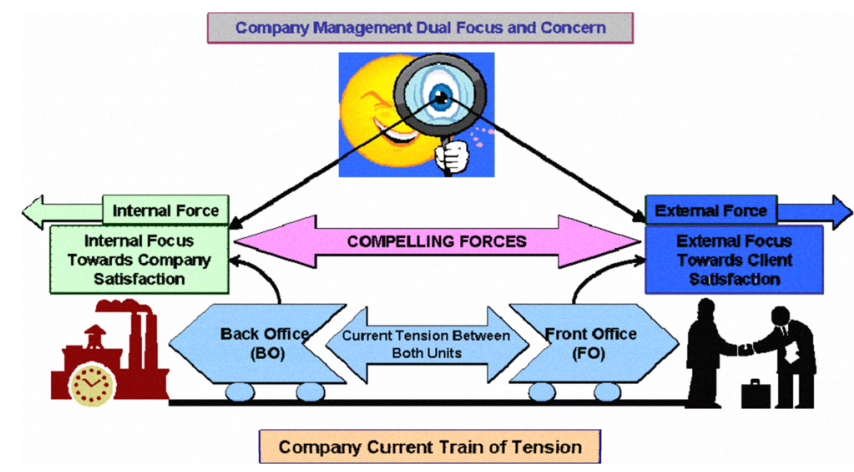

Concern and the Train of Tension

The situation may be like two wagons of a train each pulling in different directions (see Fig 2); it is a train of tension between the two units. This tension must be eased.

\section{THE SYSTEMS VIEW AND ITS PROMISE FOR PSS}

The two offices could be regarded as a system of systems, the characteristics of which [11] include managerial and operational independence. The Back Office and Front Office can each operate as isolated units (in principle) with the Back Office producing products and the Front Office providing services. The organization that seeks to move from product focused to PSS is, in effect, seeking the emergent property of an effective product-service commercial offering. Systems of systems (SoS) are characterized by the following key features: managerial, operational and technical independence among the individual systems within the SoS; evolutionary in nature; susceptible to emergent behaviours; and geographically dispersed. This latter indicates that it is information that is transferred between the component systems of the SoS. Interoperability is the defining attribute that distinguishes a SoS from a monolithic system [12]. Jamshidi [13] has offered the following practical definition of a SoS: it 'is a supersystem comprised of other elements that themselves are independent complex operational systems and interact among themselves to achieve a common goal.' It is reasonable, then, to assert that a systems approach is required to resolve the complex situation of the train of tension.

The idea and concept of systems thinking stems from work done by the founder of the General Systems Theory, Bertalaffney [14] and more recently by [15]-[16] and [17]. Reference [18] defined the systems approach as a technique that represents a broad-based systematic approach to problems that may be interdisciplinary. Its usefulness increases with problem complexity because it permits the manager or engineer to take a broad overview of the problem under consideration. The systems approach is mainly used as a problem-solving technique and as a decision-making methodology. Its application is sound in all fields of engineering that require a lot of systematic procedures for solving its problems. Nevertheless, in solving management problems it can also be of great use, as it facilitates the understanding of the complicated managerial problems and helps managers to perform good decisionmaking processes.

It is being increasingly recognized that organizations must upskill in terms or their systems capabilities to address increasingly complex problem situations and meet the challenges of sustainability and globalization [19]. It is important to recognize that this must be achieved by raising both the awareness and the expertise of the whole work force in terms of systems thinking. This is a very appropriate consideration for PSS.

In general, the transformation from product-centric to PSS must imply that the Front Office will lead the Back Office (see Fig 3.). However, it should be understood that the concerns of the Back Office with Intellectual Property, design skills, etc. cannot (and should not) be overlooked. Nevertheless, for the purposes of transformation, a central leadership and infrastructure office is needed. As with all systems of systems, the distinguishing feature (compared with a monolithic system) and that area that must be developed is interoperability. In the case of PSS, it is the interoperability between the Back Office and Front Office that must be managed. This is the role of the central leadership function; this can be considered as the third system in the system of systems. In this case the third system is one introduced to the system of systems with the purpose of improving the interoperability between the Front Office and Back Office.

It is helpful in analyzing these systems to architect them in terms of roles. The role of the Front Office is to manage client expectations and to be responsive to client service needs. An important activity is the feedback of changes in client aspirations and requirements together with horizon scanning to ensure the company is sustainable in a changing business environment. The Back Office, on the other hand, is concerned with cost-efficient production and the provision of the capabilities that constitute service support. The capabilities - realized through the usual set of people, process, products, access to technologies, and facilities must be maintained and developed in accordance with the future needs of the business. A challenge for the Back Office in the transformation from product-focused to PSS is 
to enhance responsiveness such that it can meet the demands of Front Office service needs.

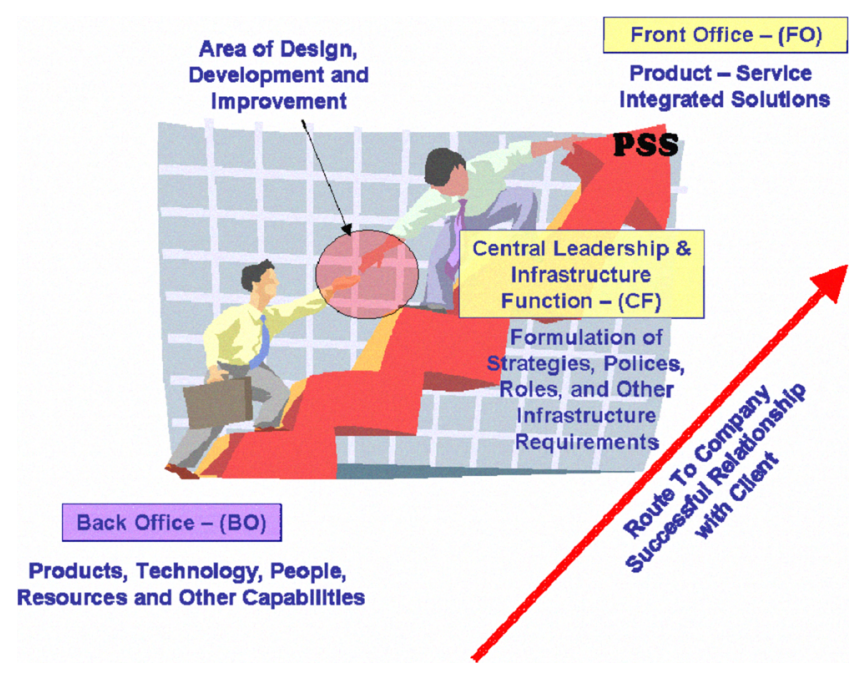

Fig. 3. Future Company Focus for Improving ClientCompany Relationship

The central function must translate company strategy into an integrative set of activities between Front Office and Back Office, and provide the principles through which the competing objectives of Front Office and Back Office can be resolved. This can be achieved by architecting the two offices in terms of roles, i.e. the set of roles and interactions that are necessary for discharge of the office responsibilities, and then providing the interactions between roles in Front Office and Back Office to achieve interoperability.

NCOIC [20] has suggested nine levels of interoperability expressed within the three broad layers of Network Transport, Information Services, and People and Processes. This spectrum of interoperability, although derived for the defense network centric warfare concept, is applicable to all systems of systems. The central function in our model, must manage interoperability across the whole spectrum between Back Office and Front Office. That is, it must ensure that data and information systems are fully and efficiently integrated, that processes within each office are properly interfaced, that planning is carried out collaboratively, and that policy is derived with respect to maintaining the strategic balance between Front Office and Back Office objectives and characteristics.

\section{MANAGING THE TRANSITION TO THE TRAIN OF BALANCE}

Although some companies appear to have mastered the solutions game (e.g. IBM, HP, and ABB), this did not happen immediately. In general, companies suffer early trials and failures before reaching a successful position in which they are more aware of their comparative and competitive advantages and, thus, able to align company capabilities with client needs. Using our simile of a train of tension with the Back Office culturally driving towards a product-focused set of business objectives and the Front Office pulling towards a client-centric service set of business objectives (see Fig. 4), we can consider the process through which these tensions will be eased to deliver a balanced PSS commercial position. It is stating the obvious to observe that such a transformation cannot happen overnight, but will be brought about through a series of steps. The objective though is to ensure that those steps are progressed smoothly with as little back-stepping as possible and that the business remains viable and competitive at each step. The systems of systems perspective that architects the enterprise in terms of roles and their interactions will provide a plan for easing the tension through a series of viable steps. The central function, that comprises both leadership and integration activities will deliver this strategy.

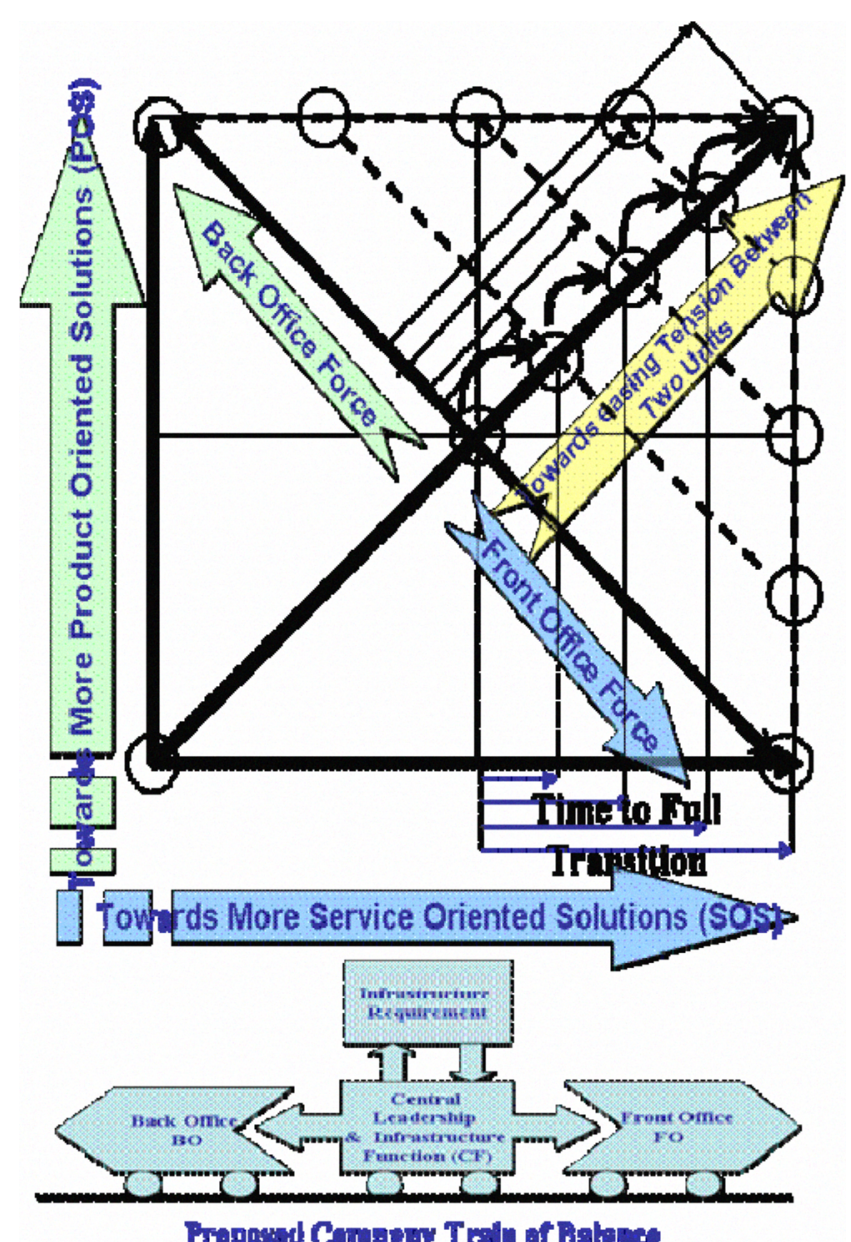

Fig. 4. Easing the Tension Between Product and Service Through Stepped Moves Towards A Win-Win Situation

We must pause to consider what a practical form of the central function might be. Clearly it must be linked strongly to the senior management of the organization and reflect the overarching policy and strategic objectives of the company. Because our focus in this paper is the transformation from product to PSS, it is reasonable to assume that one part of that overarching strategy will be the transformation itself. It must manage the interoperability between the Front Office and Back Office at every level and in every aspect of interoperability. For instance, it has the role of regulating 
decentralized decision making within the Front Office and Back Office to ensure consistency at the strategic level; this can be considered directly as part of the interoperability spectrum concerned with collaborative planning. The central function could be constituted as a specific transformation office, or a collaborative entity staffed by senior members of Front Office and Back Office. However constituted, it is important that the function is recognized explicitly and that it is continued as a function even after the transformation is considered to have taken place, because the tensions will continue to arise due to the different timescales applicable to each endeavour.

Perhaps, though, a primary role for the central function is to manage the transformation of the corporate mindset from either product or service oriented perspective to a PSS mentality. We have argued above that the organization could be considered to be a system of systems. The importance of SoS is increasingly recognized [21] and there are many advances being made towards practical solutions for SoS problems. Jamshidi's definition [13] asserts that the individual systems within a SoS interact to achieve a common goal, but it is important to realize that common understanding of the goal requires alignment of perspectives of the contributing socio-techno systems. The central function must, then, be staffed by people with a systems perspective and should include key systems skills such as enterprise architecting. The development of the overall organization towards PSS will be achieved with less risk, cost, and time (and pain!) if the systems skills within both the Back Office and Front Office are increased. The central function should then instigate and manage a strategic upskilling programme in systems. Organizations in other domains (e.g. [19]) have achieved this through a specific classification of the systems skill sets required and assessment of the proportion at each level of competence required to fulfill the organization's strategic objectives. Systems skills will be a defining characteristic of success in achieving the transformation from product to PSS.

\section{CONCLUSIONS}

This research paper describes a systems approach to reconcile company internal capability with client external demand by transforming the 'train of tension' that is created by the strategic objective of moving from product-focused to PSS business paradigm - the 'train of balance'. The transformation will be achieved by reconstructing the organization as a conceptual system of systems and creating a central function to enable effective interoperability between the front and back offices. The central function must be staffed by people with a systems perspective and with appropriate systems skills to architect the transformation, based on an understanding of the key roles within the front and back offices and how they interact. We have proposed a model for reconciling the culturally different perspectives of the front and back offices, recognizing that this must be achieved through a series of viable steps. The detailing of the techniques for deriving those steps explicitly is a subject of current research. The central function we propose must be explicitly recognized by a company trying to achieve the transformation. An important enabler that the central function will manage is the appropriate upskilling of the front and back offices in systems thinking and engineering.

\section{REFERENCES}

[1] V. Crute, G. Parry, J. Mills, "Delivering Through-life Support in a Multi-Organisational Environment: Untangling the Challenge in Parallel Transitions", $9^{\text {th }}$ Int. conf. Knowledge, Culture and Change Management, Boston, US, June 2009.

[2] D. Miller, Q. Hope, R. Eisenstat, N. Foote and J. Galbraith, "The problem of solutions: balancing clients and capabilities", Business Horizons, vol. 45, Issue 2, March-April 2002, pp. 3-12.

[3] A. Davies, T. Brady and M. Hobday, "Charting a path toward integrated solution", MIT Sloan Management Review, Spring 2006, vol. 47 no.3. pp. 36-48.

[4] R. J. Glushko, L. Tabas, "Bridging the "Front Stage" and "Back Stage" in service system design", School of Information, UC Berkeley, Berkeley, California, UCB ISchool, June 2007. Report 2007-013.

[5] A. Davies, "Moving base into high-value integrated solutions", Industrial and Corporate Change, Oxford University Press, vol. 13 no. 5, October 2004, pp. 727-756.

[6] T. S. Baines, et al. "State-of-the-art in product-service systems", Proc. IMechE, 2007, vol. 221, Part B: J. Engineering Manufacture Proceedings of the Institution of Mechanical Engineers, no 10/2007, pp.1543-1552.

[7] M. Goedkoop, M., C. van Haler, H. te Riele, P. Rommers, "Product Service-Systems, ecological and economic basics", Report for Dutch Ministries of Environment (VROM) and Economic Affairs (EZ), 1999.

[8] O. K. Mont, "Clarifying the concept of product-service system", Journal of Cleaner Production, vol. 10, issue 3, June 2002, pp. 237245.

[9] R Oliva, and R. Kallenberg, "Managing transition from products to services", International Journal of Service Industry Management, 2003, Vol. 14 No. 2, pp. 160-72.

[10] E. Manzini, C. Vezzoli, G. Clark, "Product service systems: using an existing concept as a new approach to sustainability". Journal of Design Research. 2001, vol. 1 no. 2.

[11] M. W. Maier, (1998), "Architecting Principles for Systems-ofSystems", Systems Engineering, 1:4, 267-284

[12] S. Mittal, B.P. Zeigler, J.L.R. Martin, F. Sahin, and M. Jamshidi, (2009), 'Modelling and Simulation for Systems of Systems Engineering', in Systems of Systems Engineering, Ed. By Mo Jamshidi, Wiley.

[13] Jamshidi M. (2009), 'Introduction to systems of systems', in Systems of Systems Engineering, ed. Mo Jamshidi, Wiley

[14] L., V. Bertalanaffy, "General System Theory: a critical review", in Systems Behavior, Third Edition, Ed. by the Open Systems Group, Harper and Row Publishers, London. 1981, pp. 59- 79.

[15] R. L. Ackoff, "The System Revolution", organizations as systems, Ed by Martin Lockett and Roger Spear, The Open University Press, Milton Keynes, England, 1980, pp. 26- 33.

[16] G. M. Jenkins, "The Systems Approach", in Systems Behavior, Third edition, Ed. by the Open Systems Group, Harper and Row Publishers, London. 1981, pp. 142-168.

[17] P. B. Checkland, "Science and Systems Movement", in Systems Behavior, Third Edition, Ed. by the Open Systems Group, Harper and Row Publishers, London. 1981, pp. 26- 43,

[18] D. D. Meredith, K. W. Wong, R. W. Woodhead, R. H. Wortman, "Design and Planning of Engineering Systems", 1973, Printice-Hall, Inc., Englewood Cliffs, New Jersy.

[19] Gadsden, J., Oxenham D. and Sharp L. (2008), Report from the Dstl/SEIC Systems Skills Workshop July 2008 (DSTL/TR31349), http://www.dstl.gov.uk/systemsskills/docs/SEIC_SystemsSkillsWorks hop15Jul08Report\%20v1FINAL.pdf

[20] End to End Service View of Interoperability, The role of NCOIC Deliverables, Oct07. Available at: $\mathrm{http}: / /$ issuu.com/ssimkin/docs/ncoic_deliverables_10_2007

[21] D. DeLaurentis, C.Dickerson, \& M. DiMario (2007), "A Case for an International Consortium on System-of-Systems Engineering", IEEE Systems Journal 1(1), 68-73 